\title{
Synthesis of Mn(II) Complexes-Carboxymethyl Chitosan Schiff Base Salicylaldehyde and Antibacterial Activity
}

\author{
Ismiyarto*, Niken Windi Saputri, Liswinda Zafirah Rahmatia, Purbowatiningrum Ria \\ Sarjono, Ngadiwiyana, Nor Basid Adiwibawa Prasetya, Damar Nurwahyu Bima
}

\author{
Department of Chemistry, Faculty of Science and Mathematics, Diponegoro University \\ Jl. Prof. H. Soedarto SH Tembalang, Semarang 50275, Indonesia \\ *Corresponding author: ismiyarto@live.undip.ac.id
}

Received: February 2021; Revision: April 2021; Accepted: May 2021; Available online: June 2021

\begin{abstract}
The development of compounds with a better antibacterial activity is highly needed. One way to achieve this is by modifying the structure of the compound using chitosan as a starting material, because of its abundant natural source in Indonesia, its biodegradable properties, and its structure where free amines are present. This study aims to obtain $\mathrm{Mn}$ (II) -Carboxymethyl Chitosan Schiff Base-Salicylaldehyde complex to increase its antibacterial activity against Staphylococcus aureus (Gram positive) and Escherichia coli (Gram negative). Schiff Base carboxymethyl chitosan-salicylaldehyde was synthesized from carboxymethyl chitosan with salicylaldehyde. Next, the Schiff Base Carboxymethyl Chitosan-Salicylaldehyde was complexed with $\mathrm{MnCl}_{2} \cdot 4 \mathrm{H}_{2} \mathrm{O}$ and then characterized by FTIR, UV-Vis Spectrophotometer, and AAS and tested for antibacterial activity with the disc diffusion method against Staphylococcus aureus and Escherichia coli. The product of Carboxymethyl Chitosan Schiff Base-salicylaldehyde is a brownish yellow solid with a yield of $64 \%(\mathrm{w} / \mathrm{w})$ and has antibacterial activity against Staphylococcus aureus (clear zone diameter $11 \mathrm{~mm}$ ) and Escherichia coli (clear zone diameter $13 \mathrm{~mm}$ ). The product of $\mathrm{Mn}$ (II) Complexes-Carboxymethyl Chitosan Schiff Base-salicylaldehyde is a black solid with a yield of 59\% (w/w) and has antibacterial activity against Staphylococcus aureus (clear zone diameter $13 \mathrm{~mm}$ ) and Escherichia coli (clear zone diameter $17 \mathrm{~mm}$ ).
\end{abstract}

Keywords: Antibacterial activity, carboxymethyl chitosan, $\mathrm{Mn}(\mathrm{II})$ complexes, schiff base

DOI: $10.15408 / j k v \cdot v 7 i 1.19866$

\section{INTRODUCTION}

One attempt to overcome health problems caused by bacteria is the development of antibacterial compounds with a better antibacterial activity. One of the compounds that can be used as antibacterial is chitosan, which is a modification of chitin that is abundant in nature (Shanmugam et al., 2016), and is the largest structural component of crustacean skin found in shrimps and crabs, also found on walls of fungal cells (Kurozumi et al., 2019). Chitosan is also biocompatible, biodegradable, non-toxic, non-immunogenic and non-carcinogenic; therefore, chitosan has prospective applications in various fields such as biomedicine and wastewater treatment (AlIssa et al., 2017). Chitosan is a cationic polymer, so it can interact with phospholipids from the negatively charged Gram negative bacterial cell walls (Yin et al., 2012). As a result, chitosan has better antibacterial activity against Gram negative bacteria than Gram positive because the cell walls of Gram positive bacteria do not contain phospholipids (Fouda et al., 2013).

Chitosan has low solubility in water, which limits its overall usefulness (Darmokoesoemo et al., 2018). To overcome these limitations, chemical modification of chitosan is carried out, one example is carboxymethyl chitosan (Rahmani et al., 2016). Carboxymethyl chitosan is formed from the carboxymethylation reaction with monochloroacetic acid. Carboxymethyl chitosan has a higher water solubility than chitosan, so it is expected to have better antibacterial activity than chitosan, where the $\mathrm{COOH}$ group on carboxymethyl chitosan can 
form a hydrogen bond with the hydrophilic part of the bacterial cell membrane (Fei Liu et al., 2001). In addition, chitosan has a primary imine group so that it can be modified to become a Schiff bases. Schiff bases are compounds that have an imine functional group (>C=N-) (Tamer et al., 2016), where the group has a lone pair on $\mathrm{N}$ which can form hydrogen bonds with the hydrophilic part of the bacterial membrane (Nworie et al., 2016). Schiff bases have lone pairs that can be donated to a central atom in the formation of complexes with metal Mn. Mn metal has biocompatible properties, where small amounts of Mn plays a role in biochemical reactions in the body, therefore Mn metal can be applied in the biomedical world (Ali \& Iqbal, 2017). Metal atoms easily lose electrons and form positively charged ions which are easily dissolved in biological fluids. The formation of positive ions makes it easier to interact with electron-rich biomolecules such as DNA. On the other hand, metal-ligand combinations make it possible to design new entities with various physical properties and chemical reactivity, which includes charge, solubility, rate of ligand exchange, strength of metalligand bonds, Lewis acidity, and ligand conformation. Therefore, compared to organic pharmaceuticals, the structural and electronic properties of complex compounds are of great interest in medicinal chemistry developments, especially as antimicrobial agents with new methods of action to treat diseases that are already drug resistant (Claudel et al., 2020).

Previous research has been carried out on the synthesis of Schiff base carboxymethyl chitosan-salicylaldehyde and its antibacterial activity test by Abdel-Monem et al., (2020). Research on the formation of the Mn(II)-base Schiff carboxymethyl chitosan-salicylaldehyde complex as a result of the reaction between the Schiff carboxymethyl chitosan-salicylaldehyde base with $\mathrm{MnCl}_{2} \cdot 4 \mathrm{H}_{2} \mathrm{O}$ has never been reported. It is expected that the $\mathrm{Mn}$ (II)-Schiff base carboxymethyl chitosan-salicylaldehyde complex has a better antibacterial activity than chitosan and other chitosan derivatives.

\section{MATERIALS AND METHODS Tools and Materials}

The tools used in this study were a research standard glass instrument, a Ubbelohde viscometer, a reflux device, an analytical balance, Laminar Air Flow, a
Memmert IN55 incubator, an orbital shaker, autoclave, $10-100 \mu \mathrm{L}$ micro pipette, ose needle, petri dish, spreader, tweezers, Hitachi UH5300 UV-Vis (Ultraviolet-Visible) spectrophotometer, Shimadzu Prestige 21 Fourier Transform Infrared (FTIR) spectrophotometer, and Perkin-elmer Analyzer 100 Atomic Absorption Spectrophotometer (AAS).

The materials used in this study were salicylaldehyde p.a (Merck), chitosan (Chimultiguna), monochloroacetic acid (Merck), isopropanol (Brataco), glacial acetic acid p.a (Merck), $\mathrm{NaOH}$ (Merck), $\mathrm{MnCl}_{2} 4 \mathrm{H}_{2} \mathrm{O}$ (Merck), ethanol p.a. (Merck), distilled water, nutrient agar (Merck), peptone (Merck), yeast extract (Merck), Whatman filter paper No. 42, universal indicator, amoxicillin, and $70 \%$ alcohol.

\section{Procedure}

This research begins with the identification of commercial chitosan used, followed by the synthesis of carboxymethyl chitosan by reacting chitosan with monochloroacetic acid, then the analysis by FTIR and test for antibacterial activity. Next, the synthesis of the Schiff carboxymethyl chitosan-salicylaldehyde base and the Schiff carboxymethyl chitosan-benzaldehyde base was carried out, followed by analysis with UVVis, FTIR spectrophotometry and antibacterial tests. After that, the Schiff base carboxymethyl chitosan-salicylaldehyde was complexed with $\mathrm{MnCl}_{2} \cdot 4 \mathrm{H}_{2} \mathrm{O}$ and the product was analyzed by spectrophotometry UV-Vision, FTIR and AAS and tested for its antibacterial activity.

\section{Identification of Chitosan Used for Synthesis

Determination of the Degree of Deacetylation}

Chitosan, which will be used for synthesis was analyzed by infrared spectrophotometry. Using the infrared spectra, the degree of deacetylation (DD\%) can be calculated with the base line method, by comparing the absorbance in the wavenumber of the $\mathrm{N}$-acetyl group (1650-1500) $\mathrm{cm}^{-1}\left(\mathrm{~A}_{1655}\right)$ with the absorbance at the $\mathrm{NH}_{2}$ group wave number (3500-3200) $\mathrm{cm}^{-1}\left(\mathrm{~A}_{3450}\right)$. From the FTIR spectra of chitosan, the degree of deacetylation was determined using the base line method. 


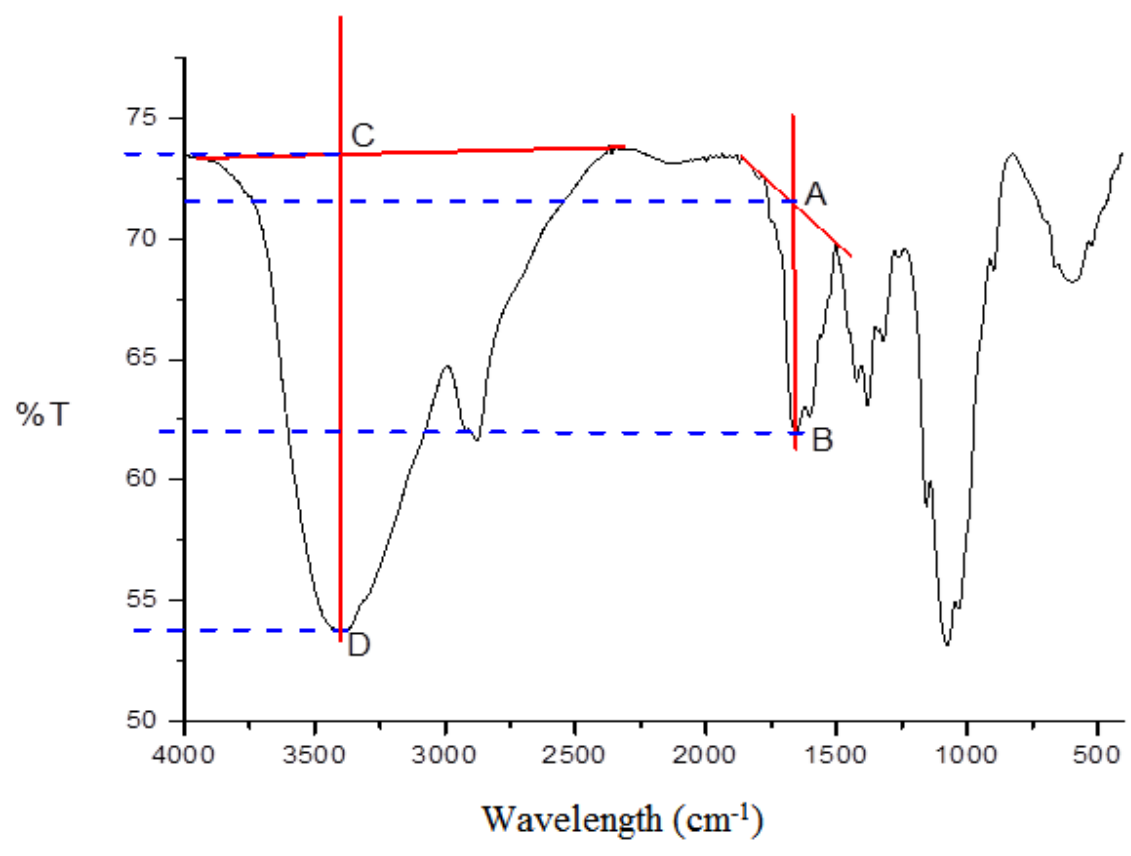

Figure 1. IR spectra for the determination of the degree of deacetylation using the base line method from the graph above, the degree of deacetylation is determined by the formula $\% \mathrm{DD}=100-\left[\left(\frac{A_{1652}}{A_{3401}}\right) \times \frac{\mathbf{1 0 0}}{\mathbf{1 . 3 3}}\right](\mathrm{Khan}$ et al., 2002)

Where \% DD is the degree of deacetylation, $\mathrm{A}_{1652}$ is the carbonyl absorption of the amide, $\mathrm{A}_{3401}$ is the hydroxyl absorption used as the internal standard and the value of 1.33 is the ratio of $A_{1655}$ and $A_{3401}$ in the complete deacetylation process.

\section{Molecular Weight Determination}

The determination of the molecular weight was carried out by the viscometrical method. $1 \mathrm{~g}$ of chitosan is dissolved in a mixture of acetic acid and $\mathrm{NaCl}$ solution in a ratio of 3:1. The concentration of chitosan solution was varied to $0.1 \% ; 0.2 \% ; 0.3 \%$ and $0.4 \%$ and $0.5 \%$. After that, the flow time was measured with the Ubelohde Viscometer. Then, the determination of the molecular weight was carried out using the MarckHouwink equation.

\section{Synthesis of Carboxymethyl Chitosan} (Darmokoesoemo et al., 2018)

Three mole variations of monochloroacetic acid 3.25; 4.23; and 9.10 mmol in different three-neck flask was dissolved with $2 \mathrm{~mL}$ of isopropanol, then the solution is added slowly into $1 \mathrm{~g}$ of chitosan (6.12 $\mathrm{mmol}$ ) which has been dissolved with 40
$\mathrm{mL}$ of $2 \%(\mathrm{v} / \mathrm{v})$ acetic acid and $1.35 \mathrm{~g}$ of $\mathrm{NaOH}$ was added. The solution mixture was stirred and heated at $50{ }^{\circ} \mathrm{C}$ for 4 hours. The product is precipitated with ethanol. The precipitate obtained was filtered with a Buechner funnel and washed with distilled water and $70 \%$ ethanol, then dried at a temperature of $50-80{ }^{\circ} \mathrm{C}$. Each carboxymethyl chitosan was analyzed by FTIR spectrophotometry and tested for its antibacterial properties.

\section{Synthesis of Schiff Base Carboxymethyl Chitosan-Salicylaldehyde (Darmokoesoemo et al., 2018) \\ Schiff's base was synthesized by} reacting $1 \mathrm{~g}$ of carboxymethyl chitosan (CMC) the result was then dissolved in $20 \mathrm{~mL}$ of $2 \%$ acetic acid with $0.00137 \mathrm{~mol}$ of salicylaldehyde or $0.00147 \mathrm{~mol}$ of benzaldehyde (benzaldehyde was used as a comparison to determine the effect of substituents in benzene on antibacterial activity) in ethanol (1:1). Then the mixture was refluxed at $50-60{ }^{\circ} \mathrm{C}$ for 5 hours, then precipitated using $5 \% \mathrm{NaOH}$. The precipitate is filtered over a Buechner funnel and washed with distilled water and ethanol and dried 
using an oven at $50{ }^{\circ} \mathrm{C}$. The product was characterized by UV-Vis spectrophotometry ( $2 \%$ acetic acid solvent), FTIR spectrophotometry and tested for its antibacterial activity.

Synthesis of the Complex of Mn(II) - Schiff Base Carboxymethyl ChitosanSalicylaldehyde (Barbosa et al., 2017)

The Schiff base complex was obtained by reacting $0.2 \mathrm{~g}$ Schiff base carboxymethyl chitosan-salicylaldehyde and the synthesized result was then dissolved in $20 \mathrm{~mL} 2 \%$ acetic acid and $0.27 \mathrm{~g}(0.00136 \mathrm{~mol}) \mathrm{MnCl}_{2} \cdot 4 \mathrm{H}_{2} \mathrm{O}$ in $20 \mathrm{~mL}$ ethanol solvent which was added slowly into an alkaline Schiff carboxymethyl chitosan-salicylaldehyde solution. The mol ratio of Schiff base carboxymethyl chitosansalicylaldehyde with $\mathrm{MnCl}_{2} \cdot 4 \mathrm{H}_{2} \mathrm{O}$ is $1: 1$. The mixture was stirred and heated for 6 hours at $60^{\circ} \mathrm{C}$. The resulting product was precipitated using $5 \% \mathrm{NaOH}$ then the precipitate was filtered. The residue was then washed with distilled water and ethanol and then oven dried. The reaction product was characterized by UVVis spectrophotometry $(2 \%$ acetic acid solvent), FTIR, AAS spectrophotometry and tested for their antibacterial activity.

\section{Antibacterial Activity Test}

As much as $1 \mathrm{~g}$ of nutrient agar is dissolved in $50 \mathrm{~mL}$ of distilled water containing $0.025 \mathrm{~g}$ of yeast extract and $0.125 \mathrm{~g}$ of peptone. The mixture was stirred and then sterilized using an autoclave for 45 minutes together with a needle and a test tube. Bacteria implantation is carried out in Laminar Air Flow. The agar medium was inserted into the test tube and placed at a slope of $\pm 30^{\circ}$. Colonies of Staphylococcus aureus and Escherichia coli bacteria were planted into the media so that it tilted in the test tube by scratching with a loop needle. The results of planting the bacteria were incubated for 24 hours.

\section{Making Bacterial Inoculum}

A total of $0.05 \mathrm{~g}$ of yeast extract and $0.25 \mathrm{~g}$ of peptone were dissolved in $100 \mathrm{~mL}$ of distilled water. The mixture was stirred and put into three erlenmeyers then sterilized using an autoclave for 45 minutes with a loop needle. Bacterial stocks that have been incubated for 24 hours were suspended in the nutrient broth media. The bacterial suspension was incubated for 2 hours in a shaker incubator and the absorbance measurement was carried out every 2 hours at a wavelength of $600 \mathrm{~nm}$ to obtain the same bacterial suspension turbidity with the standard solution turbidity of 0.5 McFarland scale.

\section{Test Compound Solution Preparation}

The test solution was prepared by dissolving $1 \mathrm{mg}$ of three samples of carboxymethyl chitosan, chitosan, Schiff base carboxymethyl chitosan-benzaldehyde, Schiff base carboxymethyl chitosan-salicylaldehyde and $\mathrm{Mn}(\mathrm{II})$-Schiff base carboxymethyl chitosan-salicylaldehyde complex in $10 \mathrm{~mL}$ of $2 \%$ acetic acid solution to make the concentration $100 \mu \mathrm{g} / \mathrm{ml}$. Acetic acid 2\% was used as a negative control and amoxicillin was used as a positive control.

\section{Making the Media for The Test}

A total of $0.05 \mathrm{~g}$ of yeast extract and $0.25 \mathrm{~g}$ of peptone and $2 \mathrm{~g}$ of nutrient agar are dissolved in $100 \mathrm{~mL}$ of distilled water. The mixture was stirred until homogeneous, then sterilized using an autoclave for 45 minutes along with a petri dish. Then $20 \mathrm{~mL}$ of nutrient media was poured into the petri dish and then left to allow the nutrient media to solidify.

\section{Antibacterial Activity Test}

The bacterial suspension that had met the turbidity of the standard solution with a concentration of $0.5 \mathrm{McF}$ arland was inoculated onto $40 \mu \mathrm{L}$ of solid agar media. A total of 10 $\mu \mathrm{L}$ of the test solution was dropped on to disc paper until the test solution was completely diffused. The disc paper was then placed on the surface of the nutrient media so that it was used as a test medium for further incubation of 24 hours, and observations were made at 8,12 , and 18 hours. In this study, amoxicillin solution was used as a positive control and acetic acid solution was used as a negative control. The visible zone is measured in diameter in millimeters.

\section{RESULT AND DISCUSSION}

Identification of Chitosan to be Used in the Synthesis

Determination of the Degree of
Deacetylation
The degree of deacetylation of chitosan was determined based on FTIR spectral data using the base line method. From 
the calculation, it was found that the deacetylation degree of chitosan used in this synthesis process was $76.95 \%$, which means that $76.95 \%$ of the amide groups have been successfully hydrolyzed into free $-\mathrm{NH}_{2}$ groups.

\section{Molecular Weight Determination}

In determining the molecular weight of chitosan, the graph equation is $\mathrm{y}=34143 \mathrm{x}+$ 122.02 with a $\mathrm{R}^{2}$ value of 0.9977 . From this equation, it can be obtained that the intrinsic viscosity value is 122.02 , so that according to the Mark-Houwink equation, the molecular weight of chitosan is 153846.348 Daltons. From these results it can be said that the chitosan used is a polymer with $n=949$.

\section{Synthesis of Carboxymethyl Chitosan}

Carboxymethyl chitosan results from the reaction of monochloroacetic acid, with 3 variations of monochloroacetic acid 3.25; 4.23; and $9.10 \mathrm{mmol}$, produced $6.12 \mathrm{mmol}$ chitosan in the form of a brownish yellow solid. Each carboxymethyl chitosan obtained was analyzed using FTIR spectrophotometry and tested for its antibacterial activity. The infrared spectrum of chitosan and three carboxymethyl chitosan products with monochloroacetic acid mol variations is shown in Figure 2. Chitosan shows the absorption of the carbonyl group $(>\mathrm{C}=\mathrm{O})$ acetyl at the wave number $1652 \mathrm{~cm}^{-1}$, while the carboxymethyl chitosan with 3 (mol) variations of monochloroacetic acid shows a shift in absorption to a higher wave number, with the wavenumber of 1660.00; 1669.00; and $1665.00 \mathrm{~cm}^{-1}$ which shows the presence of carbonyl uptake $(>\mathrm{C}=\mathrm{O})$ of carboxylates. This indicates that the carboxymethyl chitosan has been formed, which is indicated by the appearance of uptake $(>\mathrm{C}=\mathrm{O})$ of the carboxylate.

From the FTIR spectra, the degree of substitution was determined using the baseline method. The substitution degree of carboxymethyl chitosan was obtained resulting the mol variation of monochloroacetic acid 3.25 ; 4.23 ; and $9.10 \mathrm{mmol}$ at $38.7 \%$; $41.7 \%$ and $51.6 \%$. This indicates that the more moles of monochloroacetic used, the more acetate groups that enter the chitosan framework. However, if too much monochloroacetic is used the chitosan framework becomes saturated due to steric hindrances. For this reason, the further substitution process is limited. The yield of the product obtained in the variation of monochloroacetic acid mol was 3.25 ; 4.23 ; and $9.10 \mathrm{mmol} 43 \%$ each; $44 \%$; and $37 \%(\mathrm{w} / \mathrm{w})$.

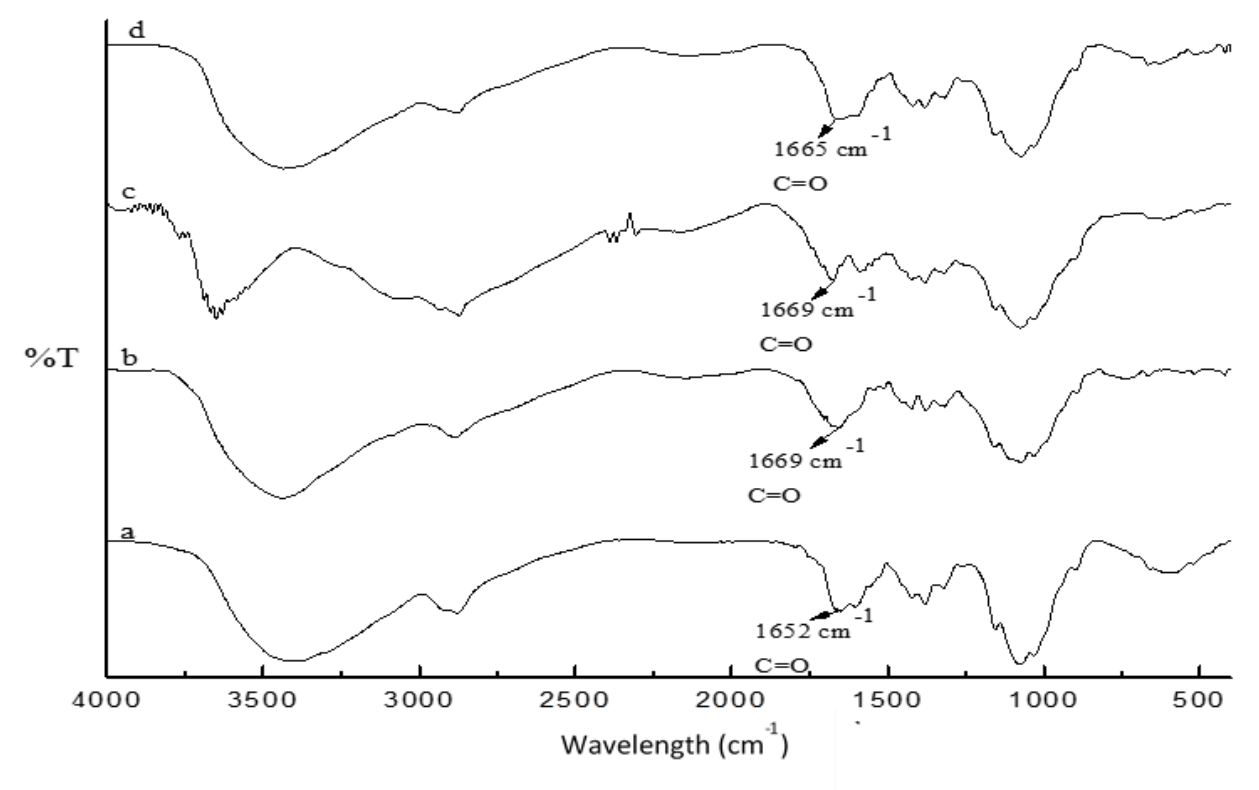

Note $=$

a : chitosan,

$\mathrm{b}$ : CMC 1 (carboxymethyl chitosan with $3.25 \mathrm{~mol}$ monochloroacetic acid),

c : CMC 2 (carboxymethyl chitosan with 4.23 mol monochloroacetic acid)

$\mathrm{d}$ : CMC 3 (carboxymethyl chitosan with 9.10 mol monochloroacetic acid)

Figure 2. IR spectra of chitosan and carboxymethyl chitosan with three variations of moles 


\section{Synthesis of Aromatic Carboxymethyl Chitosan-Aldehyde Schiff Base}

The synthesis of the Schiff base carboxymethyl chitosan-benzaldehyde and the Schiff base carboxymethyl chitosansalicylaldehyde produced a brownish yellow solid with a yield of $54 \%$ and $64 \%$ (w/w). Synthesis of Schiff base carboxymethyl chitosan-benzaldehyde was carried out to determine the effect of the hydroxyl substituent on salicylaldehyde on the antibacterial activity of Schiff base. The Schiff base product was analyzed by UV-Vis spectrophotometry and compared the spectra with carboxymethyl chitosan. From the UV-Vis spectra, a widened peak was found which was possibly caused by the result of the overlapping of several peaks, due to that deconvolution was carried out to determine the overlapping peaks of each product. The peak of the deconvolution result is shown in Table 1.

Table 1. UV-Vis Peak deconvolution results

\begin{tabular}{|c|c|c|c|}
\hline \multirow{2}{*}{ Produk } & \multicolumn{3}{|c|}{ Peak (nm) } \\
\hline & I & II & III \\
\hline carboxymethyl chitosan & 234 & 250 & 280 \\
\hline $\begin{array}{l}\text { Schiff base carboxymethyl } \\
\text { chitosan-benzaldehyde }\end{array}$ & 236 & 266 & 352 \\
\hline $\begin{array}{l}\text { Schiff base carboxymethyl } \\
\text { chitosan-salicylaldehyde }\end{array}$ & 230 & 270 & 386 \\
\hline
\end{tabular}

The deconvolution of carboxymethyl chitosan produced 3 peaks. Firstly, in the 234 $\mathrm{nm}$ area $(\varepsilon=236.92 \mathrm{~L} / \mathrm{cm} . \mathrm{mol})$ which is the $\mathrm{n}$ $\rightarrow \sigma *$ transition of the unconjugated chromophore group on chitosan. Next is in 250 $\mathrm{nm}$ which is a transition $\pi \rightarrow \pi *(\varepsilon=206.59$ L/cm.mol) carboxylic groups $(\mathrm{COOH})$ and finally $280 \mathrm{~nm}(\varepsilon=188.79 \mathrm{~L} / \mathrm{cm} . \mathrm{mol})$ which are transitions of $n \rightarrow \pi *$ carboxylate groups (-COOH) (Figure 3a).

Deconvolution of the Schiff base carboxymethyl chitosan-benzaldehyde produces 3 peaks, at a wavelength of $236 \mathrm{~nm}$ $(\varepsilon=305.23 \mathrm{~L} / \mathrm{cm} . \mathrm{mol})$ which is an $\mathrm{n} \rightarrow \sigma^{*}$ transition from the unconjugated chromophore group on chitosan, $266 \mathrm{~nm}(\varepsilon=233,85$ $\mathrm{L} / \mathrm{cm}$.mol) which is a transition $\pi \rightarrow \pi^{*}$ an imine group $(>\mathrm{C}=\mathrm{N}-)$ which is conjugated with a double bond on the benzene group and 352 $\mathrm{nm}(\varepsilon=100.57 \mathrm{~L} / \mathrm{cm} . \mathrm{mol})$ which is an $\mathrm{n}$ transition $\rightarrow \pi *$ the imine group $(>\mathrm{C}=\mathrm{N}-)$ conjugated with a double bond to the benzene group (Figure 3b).

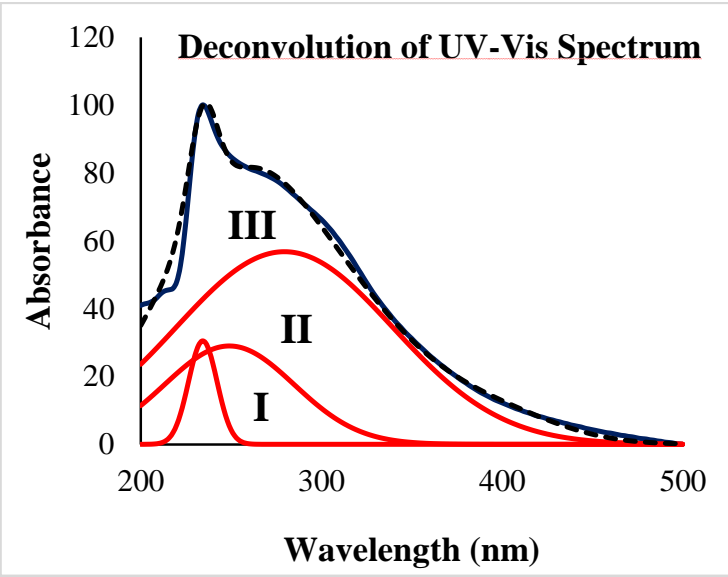

(a)

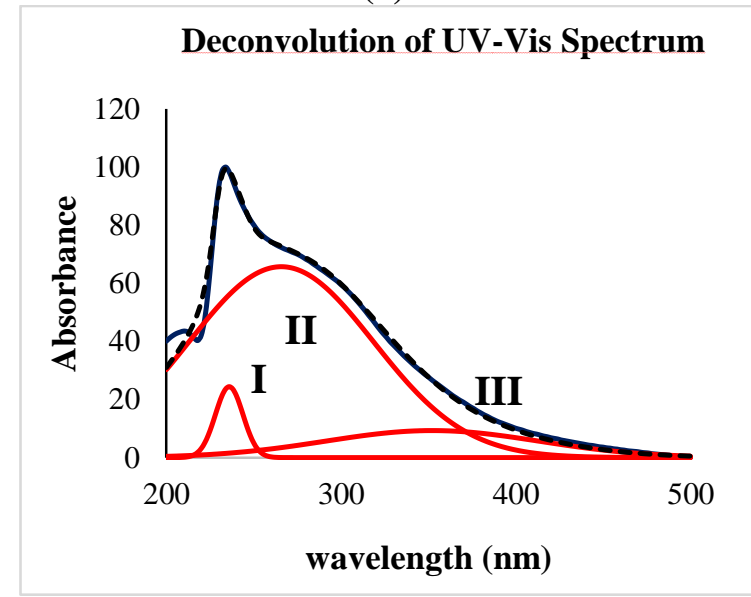

(b)

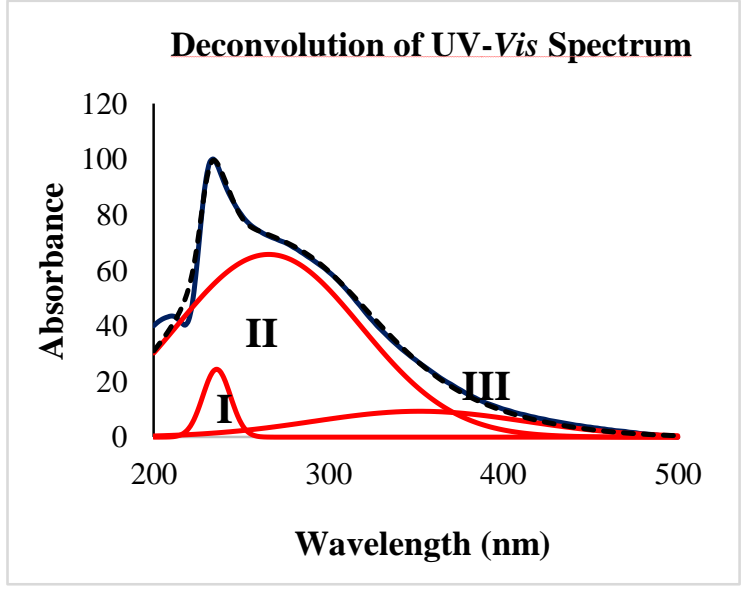

(c)

Figure 3. UV-Vis spectra deconvolution (a) carboxymethyl chitosan, (b) schiff base carboxymethyl chitosan-benzaldehyde, (c) schiff base carboxymethyl chitosan-salicylaldehyde. (peak I: peak at $236 \mathrm{~nm}$ which is the transition $\mathrm{n} \rightarrow \sigma *$, peak II: peak at $266 \mathrm{~nm}$ which is the transition $\pi \rightarrow$ $\pi *(>\mathrm{C}=\mathrm{N}-)$, peak III: peak at $352 \mathrm{~nm}$ which is the transition $\mathrm{n} \rightarrow \pi *$ the imine group $(>\mathrm{C}=\mathrm{N}-)$ 
Deconvolution of Schiff carboxymethyl chitosan-salicylaldehyde produces 3 peaks, namely at a wavelength of $230 \mathrm{~nm}(\varepsilon=321.04 \mathrm{~L} / \mathrm{cm} . \mathrm{mol})$ which is an $\mathrm{n}$ $\rightarrow \sigma *$ transition from the unconjugated chromophore group on chitosan, $270 \mathrm{~nm}$ which is a transition $\pi \rightarrow \pi^{*}(\varepsilon=246.93 \mathrm{~L} / \mathrm{cm} . \mathrm{mol})$ the imine group $(>\mathrm{C}=\mathrm{N}-)$ and the hydroxy group $(\mathrm{OH})$ substituted benzene ring conjugation and $386 \mathrm{~nm}$ which is the transition $\mathrm{n} \rightarrow \pi *(\varepsilon=76.38 \mathrm{~L} / \mathrm{cm} . \mathrm{mol})$ imine groups $(>\mathrm{C}=\mathrm{N})$ and conjugated ring-substituted benzene $(\mathrm{OH})$ groups (Figure 3c) (Ermis, 2018). There is a shift in wavelengths in bands II and III from the Schiff carboxymethyl chitosan-benzaldehyde base with the Schiff carboxymethyl chitosan-salicylaldehyde base due to the presence of hydroxyl substituents in salicylaldehyde resulting in a bathochromic shift (Tan et al., 2017).

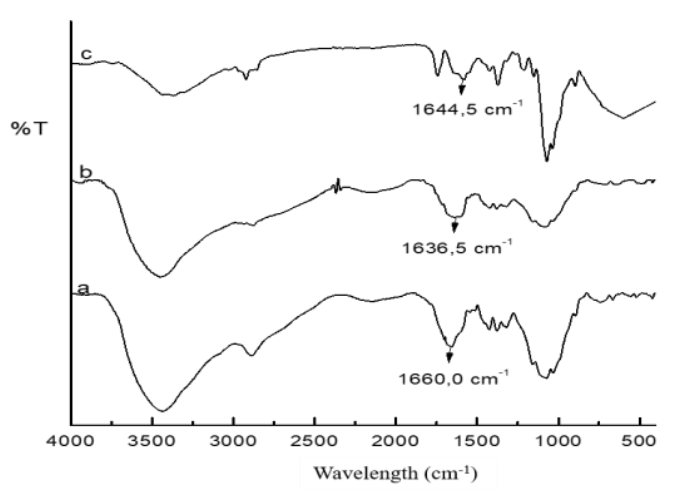

Figure 4. Infrared spectra of carboxymethyl chitosan, Schiff base carboxymethyl chitosanbenzaldehyde and carboxymethyl chitosansalicylaldehyde (a:carboxymethyl chitosan, b:Schiff base carboxymethyl chitosan-benzaldehyde, c:Schiff base carboxymethyl chitosansalicylaldehyde)

Further characterization using infrared spectrophotometry was carried out to determine the formation of groups $(>\mathrm{C}=\mathrm{N}-)$ on the Schiff base. The infrared spectrum of carboxymethyl chitosan showed the presence of group absorption $(>\mathrm{C}=\mathrm{O})$ at the wave number $1660 \mathrm{~cm}^{-1}$, while in the Schiff base carboxymethyl chitosan-benzaldehyde and

Schiff base carboxymethyl chitosansalicylaldehyde showed a shift in absorption towards a smaller wave number, which are $1636,5 \mathrm{~cm}^{-1}$ and $1644.5 \mathrm{~cm}^{-1}$. The presence of this shift indicates that the Schiff base has been formed (Barbosa et al., 2017). The infrared spectra of carboxymethyl chitosan and Schiff's base are shown in Figure 4.

\section{Complex Synthesis of Mn(II) -Base Schiff Carboxymethyl Chitosan-Salicylaldehyde}

The synthesis of Mn(II)-Schiff base carboxymethyl chitosan-salicylaldehyde complex was obtained by reacting the Schiff base carboxymethyl chitosan-salicylaldehyde with $\mathrm{MnCl}_{2} \cdot 4 \mathrm{H}_{2} \mathrm{O}$. Complexes of $\mathrm{Mn}(\mathrm{II})$-base Schiff carboxymethyl chitosan-salicylaldehyde in the form of a brownish black solid with a yield of $59 \%(w / w)$.

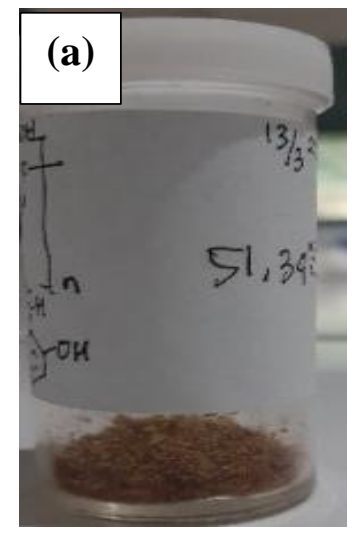

Figure 5. Schiff base products carboxymethyl chitosan-salicylaldehyde (a) and Mn(II)-Schiff base carboxymethyl chitosan-salicylaldehyde complex (b)

The Schiff base complex can be formed because of the coordination bond that occurs between the $\mathrm{C}=\mathrm{N}$ group and the $\mathrm{OH}$ group on the Schiff base carboxymethyl chitosan - salicylaldehyde with Mn metal (Iftikhar, 2018). The lone pair present on the $\mathrm{N}$ atom of the $\mathrm{C}=\mathrm{N}$ group and the $\mathrm{O}$ atom in the $\mathrm{OH}$ group causes the Schiff base to act as a ligand by donating its lone pair to the $\mathrm{Mn}$ ion which acts as the central metal ion (Malekshah et al., 2020). 


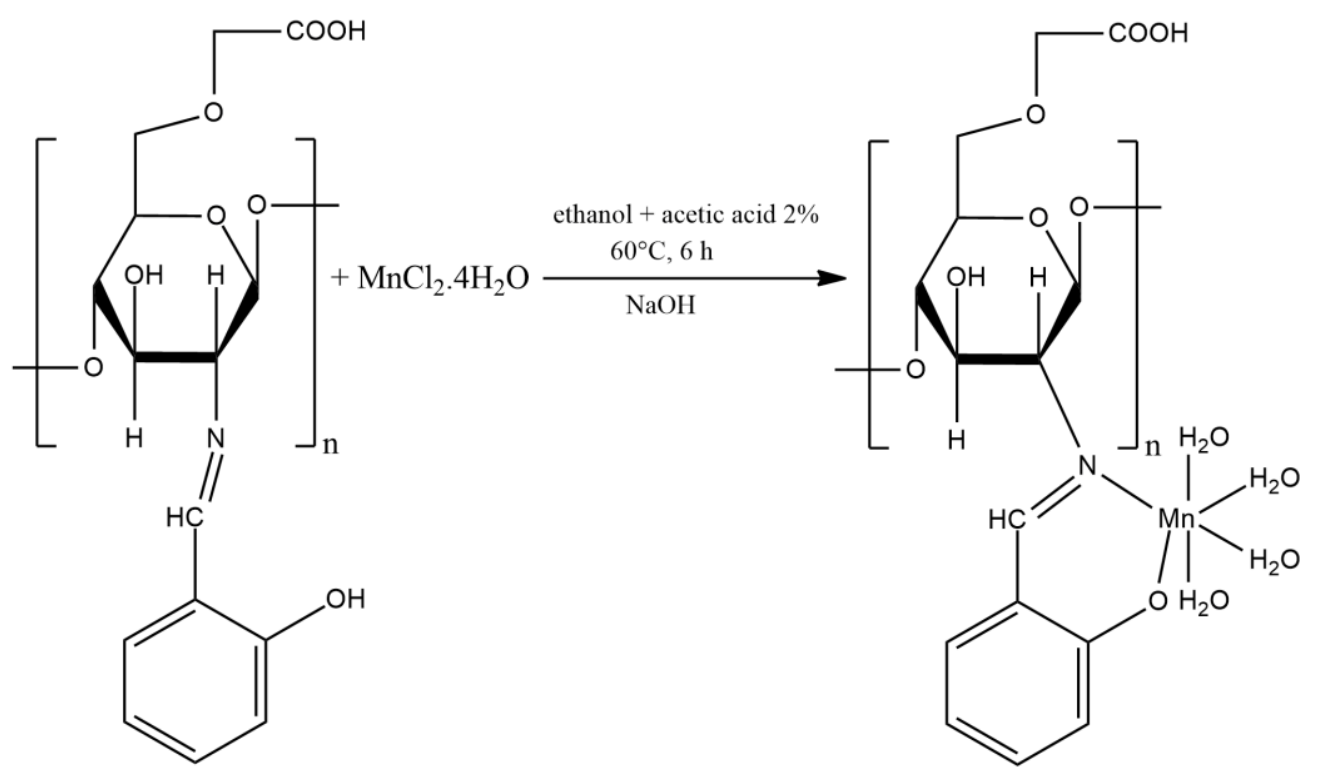

Carboxymethyl chitosan salicylaldehyde

Mn(II)-Carboxymethyl chitosan salicylaldehyde

Figure 6. The reaction for the formation of the Mn(II)-Schiff base carboxymethyl chitosan-salicylaldehyde complex

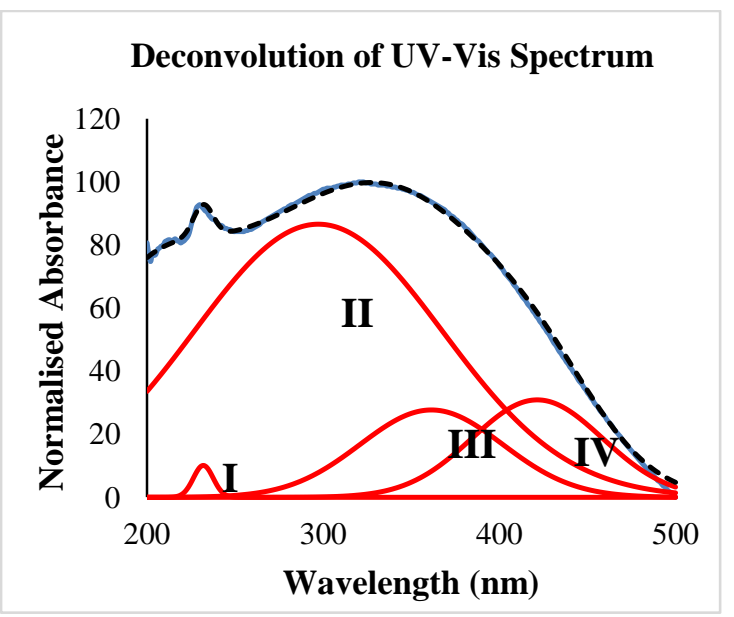

Figure 7. UV-Vis spectra deconvolution of $\mathrm{Mn}$ (II) -Schiff base carboxymethyl chitosansalicylaldehyde complex. (Peak I: peak at $236 \mathrm{~nm}$ which is the transition $\mathrm{n} \rightarrow \sigma^{*}$, Peak II: peak at 266 $\mathrm{nm}$ which is the transition $\pi \rightarrow \pi *(>\mathrm{C}=\mathrm{N}-)$, Peak III: peak at $352 \mathrm{~nm}$ which is the transition $\mathrm{n} \rightarrow \pi *$ imine group ( $>\mathrm{C}=\mathrm{N}$-), Peak IV: peak at $422 \mathrm{~nm}$ which is a transition in the Mn complex formed)

According to Martak (2018), $\mathrm{MnCl}_{2} \cdot 4 \mathrm{H}_{2} \mathrm{O}$ has a maximum wavelength of $286 \mathrm{~nm}$. The formation of the complex causes the formation of peaks in the UV-Vis spectra at a larger wavelength (bathochromic) of $422 \mathrm{~nm}$ $(\varepsilon=163.51 \mathrm{~L} / \mathrm{cm} . \mathrm{mol})$, indicating that the complex has been formed (Keypour et al., 2017). The deconvolution of the UV-Vis spectra of the Mn(II) - Schiff base carboxymethyl chitosan-salicylaldehyde complex is shown in Figure 7.

Further characterization was carried out using an infrared spectrophotometer to confirm the formation of the complex $\mathrm{Mn}$ (II)Schiff base carboxymethyl chitosansalicylaldehyde complex. Analysis with an infrared spectrophotometer gives the spectra shown in Figure 8.

The infrared spectrum of the $\mathrm{Mn}$ (II) complex, Mn(II) Schiff base carboxymethyl chitosan-salicylaldehyde, shows a shift in the absorption of the imine group $(>\mathrm{C}=\mathrm{N}-)$ towards a lower wavenumber, $1571.94 \mathrm{~cm}-1$, which indicates the coordination of the Schiff base with the central metal ion. The typical peak of complex compounds is seen in the fingerprint area, which shows the absorptions at the wavenumber of $442 \mathrm{~cm}^{-1}$ and $576 \mathrm{~cm}^{-1}$ as $\mathrm{Mn}-\mathrm{O}$ and $\mathrm{Mn}-\mathrm{N}$ groups (Kanmani et al., 2016). Mn-O and Mn-N absorption has a low intensity, this is because both are coordinating covalent bonds, where the bond strength is weaker than polar covalent bonds (Sastrohamidjojo, 2001). In addition, the absorption of the two groups is in the fingerprint area, so to find out more about the presence of $\mathrm{Mn}$ in the sample characterization was also done using AAS. 


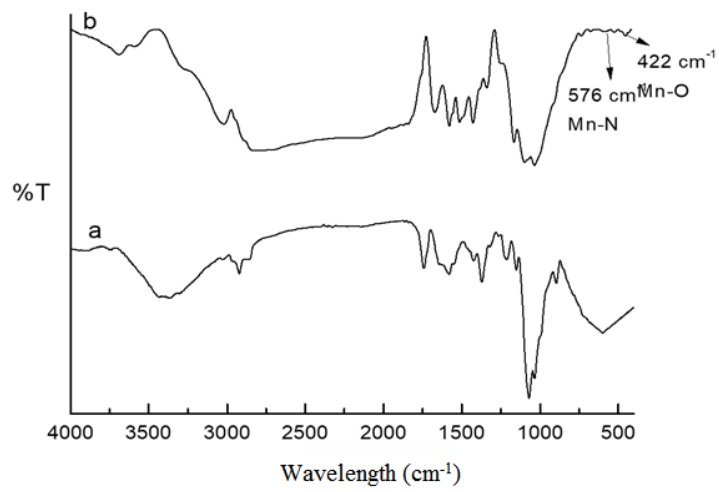

Figure 8. IR spectra of $\mathrm{Mn}(\mathrm{II})$-Schiff base carboxymethyl chitosan-salicylaldehyde complex ( a:Schiff base carboxymethyl chitosansalicylaldehyde and b:Mn(II) Schiff base carboxymethyl chitosan-salicylaldehyde complex)

Furthermore, to determine the level of $\mathrm{Mn}$ in the sample, characterization was carried out using AAS. Stoichiometrically, the Mn content in the sample was $13.69 \%$ and from the results of characterization using AAS, the Mn content in the sample was $12.74 \%$.

\section{Antibacterial Activity Test}

The clear zone diameter in this antibacterial activity test was measured at an incubation time of 12 hours. The results of the antibacterial activity test of carboxymethyl chitosan (CMC) with the best antibacterial activity can be seen in Table 2 (first experiment).

In general, the results of the antibacterial activity test of chitosan and carboxymethyl chitosan produced a larger clear zone against Gram negative bacteria (Escherichia coli) than Gram positive bacteria (Staphylococcus aureus). These data indicate that, in general, samples have a higher sensitivity to Escherichia coli bacteria than Staphylococcus aureus bacteria. The different sensitivity of carboxymethyl chitosan to Escherichia coli and Staphylococcus aureus is due to differences in the cell membrane structure of each bacteria (Fouda et al., 2013). The difference in the cell membrane structure of Escherichia coli and Staphylococcus aureus can be seen from the components of the outer membrane and the layer of the cell walls. The cell wall of Staphylococcus aureus bacteria is composed of several layers of peptidoglycan to form a thick and rigid structure that makes these bacterial cells difficult to penetrate (Silhavy et al., 2010).

Table 2. The results of the antibacterial activity test results for CMC, BS CMC 1-aromatic aldehyde and Mn(II)Schiff base carboxymethyl chitosan-salicylaldehyde complex

\begin{tabular}{|c|c|c|c|c|c|c|c|c|}
\hline \multirow{4}{*}{ No } & \multirow{4}{*}{ Compound } & \multirow{4}{*}{$\begin{array}{l}\text { concentration } \\
(\mathbf{p p m})\end{array}$} & \multicolumn{6}{|c|}{ Clear zone (mm) } \\
\hline & & & \multicolumn{3}{|c|}{ Staphylococcus aureus } & \multicolumn{3}{|c|}{ Escherichia colt } \\
\hline & & & \multicolumn{3}{|c|}{ Test } & \multicolumn{3}{|c|}{ Test } \\
\hline & & & I & II & III & I & II & III \\
\hline 1 & Chitosan & 100 & 12 & 10 & - & 13 & 11 & - \\
\hline 2 & $\mathrm{CMC} 1$ & 100 & 14 & 11 & 11 & 15 & 13 & 13 \\
\hline 3 & CMC 2 & 100 & 12 & - & - & 13 & - & - \\
\hline 4 & CMC 3 & 100 & 8 & - & - & 7 & - & - \\
\hline 5 & BS CMC 1-benzaldehyde & 100 & - & 11 & 11 & - & 13 & 14 \\
\hline 6 & BS CMC 1-salicylaldehyde & 100 & - & 15 & 12 & - & 16 & 14 \\
\hline 7 & $\begin{array}{l}\text { Mn(II)-BS CMC 1-salicylaldehyde } \\
\text { complex }\end{array}$ & 100 & - & - & 13 & - & - & 17 \\
\hline 8 & Amoxicillin (+) & 30 & 20 & 15 & 13 & 23 & 24 & 18 \\
\hline 9 & Acetate acid (-) & 2000 & 11 & 8 & 7 & 12 & 10 & 8 \\
\hline
\end{tabular}

Note:

The results of the antibacterial activity test were observed with an incubation time of 12 hours.

CMC 1, (carboxymethyl chitosan, monochloroacetic acid $(3.25 \mathrm{mmol})$

CMC 2, (carboxymethyl chitosan, monochloroacetic acid $(4.23 \mathrm{mmol})$

CMC 3, (carboxymethyl chitosan, monochloroacetic acid $(4.91 \mathrm{mmol})$

BS CMC 1-benzaldehyde = Schiff base carboxymethyl chitosan-benzaldehyde

BS CMC 1-salicilaldehyde = Schiff base carboxymethyl chitosan-salicylaldeide.

Mn(II)-BS CMC 1-salicylaldehyde complex = Mn(II)-Schiff base carboxymethyl chitosan-salicylaldehyde complex) 
In Escherichia coli, the cell wall consists of a thin peptidoglycan and an outer membrane composed of lipopolysaccharides and phospholipids. Lipopolysaccharides have hydrophilic and hydrophobic groups (Miller and Salama, 2018). The hydrophilic part can form hydrogen bonds with the carboxylate group of carboxymethyl chitosan so that it can penetrate the lipopolysaccharide layer of the outer membrane of the bacterial cell.

Based on the data in Table 2 (the first experiment), from the results of the antibacterial activity test, it is known that carboxymethyl chitosan with a variation of $3.25 \mathrm{mmol}$ of monochloroacetic acid mol (CMC 1) has a stronger antibacterial activity than chitosan, this is due to the modification of chitosan to carboxymethyl chitosan which has a carboxylic group (-COOH). It can be seen that the mol variation of monochloroacetic acid is $4.23 \mathrm{mmol}$ (CMC 2) and $4.91 \mathrm{mmol}$ (CMC 3 ), in general, there is a decrease in antibacterial activity due to an increase in molecular weight which makes it difficult for antibacterial compounds to diffuse (Yin et al, 2012). The carboxylate $(-\mathrm{COOH})$ group in carboxymethyl chitosan will undergo intermolecular and intramolecular interactions with the $\mathrm{NH}_{2}$ group to produce more $\mathrm{NH}_{3}{ }^{+}$ groups than chitosan. The $\mathrm{NH}_{3}{ }^{+}$group will interact ionically with the negative bacterial portion (Mourya et al., 2010).

The description of antibacterial activity test data for the Schiff base carboxymethyl chitosan-benzaldehyde and Schiff base carboxymethyl chitosansalicylaldehyde is shown in Table 2 (second experiment). In general, the results of the antibacterial activity test showed that the clear zone was bigger against Escherichia coli than Staphylococcus aureus bacteria. This shows that the sample has a higher sensitivity to Escherichia coli bacteria than Staphylococcus aureus bacteria. In the carboxymethyl chitosan-benzaldehyde and Schiff base carboxymethyl chitosan-salicylaldehyde, besides having a carboxylate group it also has an imine group $(>\mathrm{C}=\mathrm{N}-$ ), which allows the formation of carboxylate ions and iminium ions. With the addition of the polar groups, the interaction with the lipopolysaccharide layer of the outer membrane of the bacterial cell becomes more effective. From the results of the antibacterial activity test in Table 2 (second experiment), it is known that the
Schiff carboxymethyl chitosan-salicylaldehyde base has stronger antibacterial activity than other samples, this is due to the presence of an imine group on the Schiff base. The imine group $(>\mathrm{C}=\mathrm{N}-)$ has a lone pair on the nitrogen atom which can form a hydrogen bond with the active center of the cell. This interaction effectively disrupts the normal cell formation process (Nworie et al., 2016). In addition, the presence of -OH-substituted benzene in the Schiff carboxymethyl chitosan-salicylaldehyde base framework will increase the hydrogen bonding with the active center of the cell (Verlee et al., 2017).

Table 2 (the third experiment) shows the test data for the antibacterial activity of the Mn(II) -base Schiff carboxymethyl chitosansalicylaldehyde complex. In general, the results of the antibacterial activity test showed that the clear zone was bigger against Escherichia coli than Staphylococcus aureus bacteria. From the test results, the antibacterial activity of the complex compound $\mathrm{Mn}$ (II) Schiff base carboxymethyl chitosansalicylaldehyde has stronger antibacterial activity than other samples. This is because in a complex with a more stable structure, the metal bond to the ligand can increase the antibacterial activity of the Schiff base (Lemire, 2013). Chelate which is formed from $\mathrm{Mn}$ metal ions and basic ligands Schiff carboxymethyl chitosan-salicylaldehyde is polar, so it will easily interact with the surface of bacterial cells which is also polar, thus disrupting metabolism and growth of bacterial cells (Wang et al., 2005).

\section{CONCLUSION}

Mn(II)-Schiff base carboxymethyl chitosan-salicylaldehyde complex is a blackish brown solid with a yield of 59\% (w/w). The $\mathrm{Mn}$ (II) complex-base Schiff carboxymethyl chitosan-salicylaldehyde has the greatest antibacterial activity compared to chitosan, carboxymethyl chitosan, Schiff base carboxymethyl chitosan-benzaldehyde and Schiff base carboxymethyl chitosansalicylaldehyde against Staphylococcus aureus and Escherichia coli.

\section{ACKNOWLEDGMENT}

This research was funded by sources none other than the Diponegoro University 2020 State Budget. Number: 233-114 / UN7.6.1 / PP / 2020 


\section{REFERENCES}

Abdel-Monem RA, Khalil AM, Darwesh OM, Hashim AI, Rabie ST. 2020. Antibacterial properties of carboxymethyl chitosan Schiff-base nanocomposites loaded with silver nanoparticles. Journal of Macromolecular Science, Part A: Pure and Applied Chemistry. 57(2): 145-155. https://doi.org/10.1080/10601325.2019.16 74666

Al-Issa MA, Abbas AA, Matty FS. 2017. Synthesis and characterization of schiff base derived from chitosan and its complexes with $\left(\mathrm{Co}^{+2}, \mathrm{Ni}^{+2}\right.$ and $\left.\mathrm{Cu}^{+2}\right)$. Ibn AL- Haitham Journal For Pure and Applied Science. 29(2): 115-129.

Ali B, Iqbal MA. 2017. Coordination complexes of manganese and their biomedical applications. Chemistry Select. 2(4): 15861604.

https://doi.org/10.1002/slct.201601909

Barbosa HFG, Attjioui M, Ferreira APG, Dockal ER, Gueddari NEEl, Moerschbacher BM, Cavalheiro ÉTG. 2017. Synthesis, characterization and biological activities of biopolymeric schiff bases prepared with chitosan and salicylaldehydes and their $\mathrm{Pd}(\mathrm{II})$ and $\mathrm{Pt}(\mathrm{II})$ complexes. Molecules. 22(11):

https://doi.org/10.3390/molecules2211198 7

Claudel M, Schwarte JV, Fromm KM. 2020. New antimicrobial strategies based on metal complexes. Chemistry, 2(4): 849-899. https://doi.org/10.3390/chemistry2040056

Darmokoesoemo H, Suyanto S, Anggara LS, Amenaghawon AN, Kusuma HS. 2018. Application of carboxymethyl chitosanbenzaldehyde as anticorrosion agent on steel. International Journal of Chemical Engineering. https://doi.org/10.1155/2018/4397867

Liu XF, Guan YL, Yang DZ, Li Z, Yao KD. 2001. Antibacterial action of chitosan and carboxymethylated chitosan. Journal of Applied Polymer Science. 79(7): 13241335. https://doi.org/10.1002/10974628(20010214)79:7<1324::AIDAPP210>3.0.CO;2-L

Fouda MMG, El-Aassar MR, Al-Deyab SS. 2013. Antimicrobial activity of carboxymethyl chitosan/polyethylene oxide nanofibers embedded silver nanoparticles. Carbohydrate Polymers. 92(2): 10121017.

https://doi.org/10.1016/j.carbpol.2012.10.0 47

Keypour H, Mahmoudabadi M, Shooshtari A, Hosseinzadeh L, Mohsenzadeh F, Gable RW. 2017. Synthesis of $\mathrm{Mn}(\mathrm{II})$ and $\mathrm{Zn}(\mathrm{II})$ complexes with new macrocyclic Schiffbase ligands containing piperazine moiety: Spectroscopic, structural, cytotoxic and antibacterial properties. Polyhedron. 127(II): $\quad$ 345-354. https://doi.org/10.1016/j.poly.2017.02.008

Kurozumi S, Kiyose M, Noguchi T, Sato K. 2019. A novel hydrochloride-free chitosan oligosaccharide production method to improve taste. International Journal of Biological Macromolecules. 140: 109118.

https://doi.org/10.1016/j.ijbiomac.2019.08. 067

Malekshah RE, Shakeri F, Khaleghian A, Salehi M. 2020. Developing a biopolymeric chitosan supported Schiff-base and $\mathrm{Cu}(\mathrm{II}), \mathrm{Ni}$ (II) and $\mathrm{Zn}(\mathrm{II})$ complexes and biological evaluation as pro-drug. International Journal of Biological Macromolecules. 152(II): $\quad$ 846-861. https://doi.org/10.1016/j.ijbiomac.2020.02. 245

Miller SI, Salama NR. 2018. The gram-negative bacterial periplasm: Size matters. PLoS Biology. $\quad 16(1)$ : $1-7$. https://doi.org/10.1371/journal.pbio.20049 35

Mourya VK, Inamdar NN, Tiwari A. 2010. Carboxymethyl chitosan and its applications. Advanced Materials Letters. 1(1):

11-33. https://doi.org/10.5185/amlett.2010.3108

Nworie FS, Nwabue FI, Elom NI, Eluu SO. 2016. Schiff bases and schiff base metal complexes: from syntheses to applications. J. Basic Appl. Res., 2: 295-305.

Rahmani S, Mohammadi Z, Amini M, Isaei E, Taheritarigh S, Tehrani NR, Tehrani MR. 2016. Methylated 4-N,N dimethyl aminobenzyl N,O carboxymethyl chitosan as a new chitosan derivative: Synthesis, characterization, cytotoxicity and antibacterial activity. Carbohydrate Polymers, 149, 131-139. 
https://doi.org/10.1016/j.carbpol.2016.04.1 16

Shanmugam A, Kathiresan K, Nayak L. 2016. Preparation, characterization and antibacterial activity of chitosan and phosphorylated chitosan from cuttlebone of Sepia kobiensis (Hoyle, 1885). Biotechnology Reports. 9: 25-30. https://doi.org/10.1016/j.btre.2015.10.007

Silhavy TJ, Kahne D, Walker S. 2010. The bacterial cell envelope. Cold Spring Harbor Perspectives in Biology. 2(5): https://doi.org/10.1101/cshperspect.a00041 4

Tamer TM, Hassan MA, Omer AM, Baset WMA, Hassan ME, El-Shafeey MEA, Eldin MSM. 2016. Synthesis, characterization and antimicrobial evaluation of two aromatic chitosan Schiff base derivatives. Process Biochemistry. 51(10): 1721-1730. https://doi.org/10.1016/j.procbio.2016.08.0 02
Verlee A, Mincke S, Stevens CV. 2017. Recent developments in antibacterial and antifungal chitosan and its derivatives. Carbohydrate Polymers. 164: 268-283. https://doi.org/10.1016/j.carbpol.2017.02.0 01

Wang X, Du Y, Fan L, Liu H, Hu Y. 2005. Chitosan- metal complexes as antimicrobial agent: Synthesis, characterization and Structure-activity study. Polymer Bulletin. 55(1-2): 105113. https://doi.org/10.1007/s00289-0050414-1

Yin X, Chen J, Yuan W, Lin Q, Ji L, Liu F. 2012. Preparation and antibacterial activity of Schiff bases from O-carboxymethyl chitosan and para-substituted benzaldehydes. Polymer Bulletin. 68(5): 1215-1226. https://doi.org/10.1007/s00289-011-05994 